\title{
Comprehensive Cost Analysis and Comparison of Thermal Power, Hydropower and Wind Power in China
}

\author{
Junsong Qin \\ School of Economics and Management \\ North China Electric Power University, \\ Beijing, China \\ ncepujun@163.com \\ Yashan Zhong* \\ School of Economics and Management \\ North China Electric Power University, \\ Beijing, China \\ zhongyashan132@163.com
}

\author{
Dongxiao Niu \\ School of Economics and Management \\ North China Electric Power University, \\ Beijing, China \\ niudx@126.com \\ Meiqiong $\mathrm{Wu}$ \\ School of Economics and Management \\ North China Electric Power University, \\ Beijing, China \\ wumeiqiong92@163.com
}

\begin{abstract}
The types of power generation mainly include thermal power, hydropower and wind power in China. However, thermal power generation has accounted for 75.2 percent of the total generation. In order to adjust the proportion of the energy supply and achieve energy saving, it is vital to investigate the comprehensive cost of different power generation types. The objects are thermal power, hydropower and wind power in this paper, and the calculation methods of unit power generation cost are presented respectively. The results show that the comprehensive cost of wind power is the highest, following by the thermal power and the hydropower.
\end{abstract}

Keywords-Thermal power, Hydropower, Wind power, Comprehensive cost

\section{INTRODUCTION}

Primary energy includes fossil fuel, nuclear fuel, biomass energy, hydropower, wind energy, solar energy and so on. Hence, the power plant can be divided into thermal power, hydropower, wind power, solar power according to the different fuel used in the power plant.[1] Currently, the types of power generation mainly include thermal power, hydropower and wind power in China. According to data released by the National statistical offices, China's power generation and installed capacity ranked first over the world in 2004, the power installed capacity is 1.36 billion kilowatts and the generating capacity is 5545.9 billion $\mathrm{kWh}$, in which thermal power generating capacity is 4170.5 billion kilowatts, accounting for 75.2 percent of total, hydroelectric power is 1064.8 billion kilowatts accounting for 19.2 percent[2] , but wind power is 143.6 billion kilowatts accounting for only 2.59 percent.

In order to adjust the proportion of the energy supply and achieve energy saving, it is vital to investigate the comprehensive cost of different power generation types. The objects are thermal power, hydropower and wind power in this paper, and the calculation methods of unit power generation cost are presented respectively.

\section{COST ANALYSIS AND CALCULATION OF POWER GENERATION}

\section{A. Cost analysis and calculation of thermal power}

The total cost is divided into variable cost and fixed cost grounded on the nature of the expenses. Variable cost refers to the expenses varying with output, such as fuel, water and electricity fees, etc. While, fixed cost remains constant in a certain scale of production[4], for example employee salaries. In this section, the cost types of a power plant are as following: depreciation charge, fuel fees, water cost, material expenses, wages and benefits, operation and maintenance cost, financial and other expenses.

1) Depreciation charge.

After projects have been put into operation, the value of the fixed assets gradually transfers to the products, which is called the depreciation of fixed assets. There are three common methods to draw depreciation that are straight-line method, workload method and accelerated depreciation method. Thermal power plants generally use straight-line depreciation, and ignore the residual value. When many units are put into operation, every year, the asset original value proportion of each unit is the ratio of each generating capacity acounting for the total generating capacity. The depreciation cost can be obtained by Eq 1

$$
C_{d}=\frac{r(1+r)^{n}}{(1+r)^{n}-1} \cdot \frac{I}{P_{\varepsilon} \cdot n \cdot h \cdot(1-s)}
$$

Where $r$ is long term loan interest rate, $n$ is life of thermal power plant, $P_{\varepsilon}$ is rated power, $I$ is static total investment, $h$ 
is average annual utilization hours, and $s$ is line loss rate between generator terminal and electricity settlement point. Generally, $s=0$.

\section{2) Fuel fees.}

Cost of fuel used for power generation calls fuel fees. The fuel fee is formulated as:

$$
C_{f}=\lambda \cdot p
$$

Where $\mathrm{C}_{\mathrm{f}}$ is fuel fee of per kilowatt hour $\lambda$ is standard coal consumption rate and $p$ is standard coal price

3) Operation and maintenance cost.

Operation and maintenance cost relates to water cost, material cost wages, loan interest and so on, and it can be formulated by the following expression:

$$
C_{o}=\frac{\left(C_{r}+C_{m}+C_{w}+C_{s}\right)}{P_{e} \cdot n \cdot h}
$$

Where $C_{o}$ is operation and maintenance cost of per kilowatt hour, $C_{r}$ is major repairing cost , which is obtained by the original value of fixed asset pulsing the rate of major repairing cost, usually taken 2.5 percent, $C_{m}$ is material cost involving low-valued consumables expenses, $C_{w}$ is water expenses, $C_{s}$ is wages and benefits. Wage is the average annual wage, and welfare expense is 60 percent of total amount of wages.

\section{4) Financial expenses.}

The cost of the power plant to raise funds in the process of production and operation is called financial expenses, comprising interest expense for long-term loans and floating capital, and other financial cost [5].

\section{5) Other expenses.}

There are some expenses should be included into the cost of production, such as administrative expenses, conference fee, transportation fees, research and education fees and so on.

\section{B. Cost analysis and calculation of hydropower}

The cost of hydropower also includes fixed and variable cost, and the fixed cost takes the primary proportion. Fixed cost is consisting of dam construction costs, land acquisition cost and other large investment, which accounts for a large share of electricity price. Therefore, in the future regional power market, hydropower enterprises should pay more attention to the fixed cost. Variable cost embraces water fee, tax and other variable operation and maintenance cost.

Similarly, the cost of hydropower contains depreciation charge, fuel fees, water cost, material expenses, wages and benefits, operation and maintenance cost, financial and other expenses.

In addition, in order to describe the cost causing by a small variety in quantity of electricity, marginal electricity cost is introduced, which comprises equipment maintenance labor costs, repairing costs, management fees and other expenses. The amount of water consumed by per unit of electricity is called the comprehensive water consumption rate of hydropower station; it can be formulated by the Eq. 4 .

$$
\alpha=\frac{Q}{W}=\frac{V T}{P T}=\frac{\beta}{\eta D}
$$

Where $\alpha$ is comprehensive water consumption rate, $Q$ is total water consumption of generation, $W$ is total power generation, $P$ is output of hydropower, $\eta$ is efficiency of hydropower, $\beta$ is unit conversion constant, usually taken get 366.97, and $D$ is net water head.

\section{Cost analysis and calculation of wind power}

Currently, the actual cost of wind power generation is calculated from the perspective of the wind farm, taking the wind farm as a project, and reckoning the actual cost by the cost method of accounting theory. There is no energy consumption in the process of wind power generation[6]. Wind power generation only relies on the nature resource, and then converts wind energy into mechanical energy, and further convert into electric energy. Therefore, the total cost of wind power only comprises mechanical loss fees of wind turbines, wages and benefits, management expenses, equipment maintenance, repairing cost and financial expenses. In this section, dynamic cost calculation method is been presented, which is also called life-cycle cost. The principle of this method is that the total cost of generation should be shared equally in the whole lifetime. The total cost of wind power is formulated by Eq. 5 .

$$
C=\frac{r(1+r)^{n}}{(1+r)^{n}-1} \cdot\left(\frac{\alpha \cdot I}{8760 F}\right)
$$

Where $r$ is long term loan interest rate $\alpha$ is investment proportional coefficient, which depends on the unit capacity of wind turbines, the greater the capacity, the smaller the coefficient value, and usually gets $1.2-1.4$. I is the price of unit capacity turbines. $n$ is the lifetime of wind farm. $F$ is capacity coefficient and can be obtained by Eq. 6

$$
F=\frac{P_{a v e}}{P_{e}}
$$

Where $P_{a v e}$ is annual average output efficiency of wind turbine. $P_{e}$ is rated efficiency of turbines.

$$
P_{a v e}=\int_{v_{0}}^{v_{t}} P(v) \cdot f(v) d v
$$

Where $v_{0}$ is start-up wind speed, $v_{t}$ is cut-off wind speed, $P(v)$ is output characteristic, and $f(v)$ is probability density function of wind speed, and the probability density is formulated by the two-parameters model.

$$
f(v)=\left(\frac{\beta}{\omega}\right)\left(\frac{v}{\omega}\right)^{\beta-1} \exp \left[-\left(\frac{v}{\omega}\right)^{k}\right]
$$


Where $\beta$ is shape parameter, $\omega$ is scale parameter. The output of wind turbine is affected by wind speed, without considering the air density, humidity and other natural factors, the relationship between output power and wind speed of typical wind turbine can be expressed in the Fig 1.

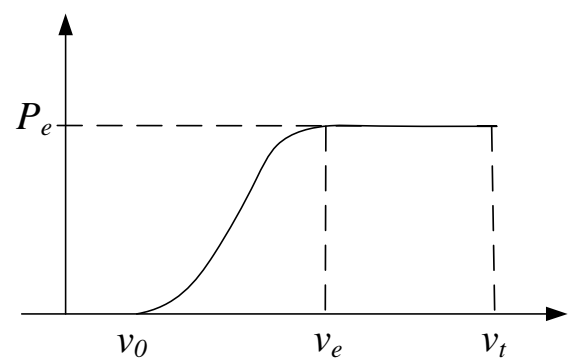

Fig. 1. Relation between output efficiency of wind turbine and wind speed
Where $v_{e}$ is rated wind speed, $\delta$ is output characteristic, which is the ratio of output power and power rating of turbine. Generally, output characteristic is expressed by a complex function concerning wind speed, and the expression can be described as linear function, quadratic function or cubic function. As the characteristics of wind turbine is more close to the polynomial expression, this study has choose the cubic function as the output characteristic function, that is $\delta=\left(v / v_{e}\right)^{3}$

\section{CASE ANALYSIS}

In this section, we have collected the basic data to calculate the cost of each type of generation using the presented method. The basic parameters of generation cost based on different energy are shown in Table 1

So the function can be established as Eq. 9.

$$
P(v)=\left\{\begin{array}{lc}
0 & 0 \leq v \leq v_{0} \\
\delta \cdot P_{e} & v_{0} \leq v \leq v_{e} \\
P_{e} & v_{e} \leq v \leq v_{t} \\
0 & v \geq v_{t}
\end{array}\right.
$$

TABLE I.

BASIC PARAMETERS OF THE COST OF DIFFERENT GENERATION TYPES

\begin{tabular}{llll}
\hline & Thermal power & Hydropower & Wind power \\
\hline Rated power & $600 \mathrm{MW}$ & $600 \mathrm{MW}$ & $50 \mathrm{MW}$ \\
\hline Annual utilization hours & $5500 \mathrm{~h}$ & $5000 \mathrm{~h}$ & $2076 \mathrm{~h}$ \\
\hline Lifetime & 20 years & 20 years & 20 years \\
\hline Power consumption rate & $5.90 \%$ & $0.20 \%$ & $4.20 \%$ \\
\hline Personnel quota & 480 people & 84 people & 36 people \\
\hline Discount rate & $7 \%$ & $7 \%$ & $7 \%$ \\
\hline Foreign exchange rate & 7 USD/RMB & 7 USD/RMB & 7 USD/RMB \\
\hline Fuel fee & 302.6 yuan per ton & 0 & 0 \\
\hline Efficiency & - & $80 \%$ & - \\
\hline Standard coal consumption rate & $289 \mathrm{~kg} / \mathrm{MWh}$ & - & - \\
\hline Depreciation & $5.00 \%$ & $5 \%$ & $5 \%$ \\
\hline Major repairing cost rate & $2.50 \%$ & $1 \%$ & $0.86 \%$ \\
\hline Comsumptive material cost & 5.9 yuan per MWh & 6.88 yuan per $\mathrm{MWh}$ & 0.24 yuan per MWh \\
\hline Loan interest & $6.07 \%$ & $6.07 \%$ & $6.07 \%$ \\
\hline Other expenses & 12 yuan per MWh & 10 yuan per MWh & 15.2 yuan per MWh \\
\hline Static total investment & 29.8 million yuan & 30.6 million yuan & 4.0584 million yuan \\
\hline Wage quota & 81000 yuan /person/ year & 80000 yuan /person/ year & 60000 yuan /person/ year \\
\hline
\end{tabular}

In accordance with the basic parameters and cost calculation methods presented above, the variable and fixed cost of each type of generation can be obtained, and the results are displayed in Table 2. 


\begin{tabular}{lllll}
\hline & & Thermal power & Hydropower & Wind power \\
\hline \multirow{5}{*}{ Variable cost } & Fuel fee(yuan per MWh) & 87.45 & 0.00 & 0.00 \\
\cline { 2 - 5 } & Comsumptive material cost(yuan per MWh) & 5.90 & 6.88 & 0.24 \\
\cline { 2 - 5 } Fixed cost & Total variable cost (yuan per MWh) & 93.35 & 6.88 & 0.24 \\
& Depreciation (yuan per MWh) & 85.26 & 96.28 & 369.06 \\
\cline { 2 - 5 } & Wages and benifits (yuan per MWh) & 11.85 & 2.24 & 20.81 \\
\cline { 2 - 5 } & Major reparing cost(yuan per MWh) & 22.58 & 10.20 & 33.62 \\
\cline { 2 - 5 } & Finacial expenses(yuan per MWh) & 63.35 & 71.55 & 224.25 \\
\cline { 2 - 5 } & Other expenses(yuan per MWh) & 12.00 & 10.00 & 15.23 \\
\hline Total fixed cost(yuan per MWh) & 195.04 & 190.27 & 662.97 \\
\hline \multicolumn{2}{l}{ Total cost(yuan per MWh) } & 288.39 & 197.15 & 663.22 \\
\hline
\end{tabular}

As we can see from the Table 2, the total cost of thermal power, hydropower and wind power is 288.39 yuan per MWh, 197.15 yuan per MWh and 663.22 yuan per MWh respectively. The results demonstrate that cost of hydropower is the lowest, following by thermal power and wind power.

\section{SUMMARY}

According to the proportion of different primary energy power generation in China, this research has selected thermal power, hydropower and wind power as subject investigated, and introduced the cost calculation methods of three generation types separately. Taking the 600MW thermal power plant, 600MW hydropower plant and 50MWwind power plant as examples, the unit costs of three kinds of power plants are gained by calculating and analyzing the basic data. Furthermore, the results demonstrate that cost of hydropower is the lowest, only 197.15 yuan per MWh, following by thermal power and wind power, 288.39 yuan per MWh and 663.22 yuan per MWh separately.

\section{REFERENCES}

[1] C. X. Luo, Current situation and Prospect of wind power generation in the world, Chinese and foreign energy, vol.3, pp. 24-31, 2012.(In Chinese)

[2] K. Yang, B. Xiao, Y. Wei, G. Tian, Economic analysis of wind power project based on average power generation cost, Science and technology and Industry, vol.10, pp. 78-80, 2010. (In Chinese)

[3] J. Z. Liu, T. Liu, C. Cui, Wind power pricing mechanism based on the cost of wind power and thermal power, China Electric Power, vol.7, pp. 89-94, 2015. (In Chinese)

[4] Z. X. Weng, L. B. Shi, etc., Dynamic economic dispatch of power system considering the cost of wind power, Chinese Journal of Electrical Engineering, vol. 4, pp. 514-523, 2014. (In Chinese)

[5] D. H. Liu, Y. P. Yang, etc., Research on power supply cost of thermal power unit considering environmental cost, China Electric Power, vol. 9, pp. 24-28, 2005. (In Chinese)

[6] Q. Zhang, Pricing of water and electricity pricing based on the accounting cost method, Journal of electric power system and automation, vol. 4, pp. 113-119, 2008. (In Chinese) 